\title{
Security as a Service
}

\author{
by Hans Braunschweiler
}

\section{Security and management}

Today, it is hardly necessary to emphasize the fact particularly that the successful existence of the enterprise as an economic unit is no longer so self-evident as it has been in former years. The achievement of commensurate profits, maintaining the substance of business or - in extreme cases - even the survival of the enterprise : all these are being endangered from various directions. In other words, the economic success of business in its widest sense is being threatened (1st diagram), from outside sources and from within. The threats from outside sources come through the growing complexity of our environment and of market conditions. Furthermore there are disrupting incidents caused through force majeure or by the behaviour of third parties. The threat from within is to be found either in the structure of business or in behavioural patterns. Here too there are disrupting events such as human error or technical failure, or activities on the part of employees against the company.

Against these four sources from which threats can arise there are appropriate defensive measures, but the complete elimination of any threat whatsoever can never be achieved. It is rather a question of counteracting the threats in the best possible way. If, on the other hand, we define security against this background of threat, then the measures necessary to meet the threat also represent a comprehensive task, one that cannot be divorced from management. In this connection the defensive measures may vary greatly, according to the premise. The threats shown on the left of our diagram could certainly be effectively encountered by an improvement in management, be it by acting suitable measures in marketing or by creating structures and behavioural patterns in line with real market conditions and involving reasonable cost. Those threats shown on the right of our diagram can be met by specific precautions against the occurrence or the consequences of disrupting events.

Security as a problem is nothing new; it is far more a question of regarding management more comprehensively than previously, also from the aspect "Risk and Security", by going further than merely considering certain risk problems. Such a way of looking at the matter has become even more urgent in the light of various current developments. I am thinking of the economic situation, which will continue to be uncertain for some time to come, the growing problems with regard to the supply of raw materials, the increasing potential dangers from larger and more complex technical equipment, the rise in crime, and many other instances. The willingness of top management to regard these matters comprehensively is also growing, and is certainly partly responsible for the fact that things are moving in the services sector.

Seen from this angle I should now like to refer to the possible spheres of influence of the services sector. 


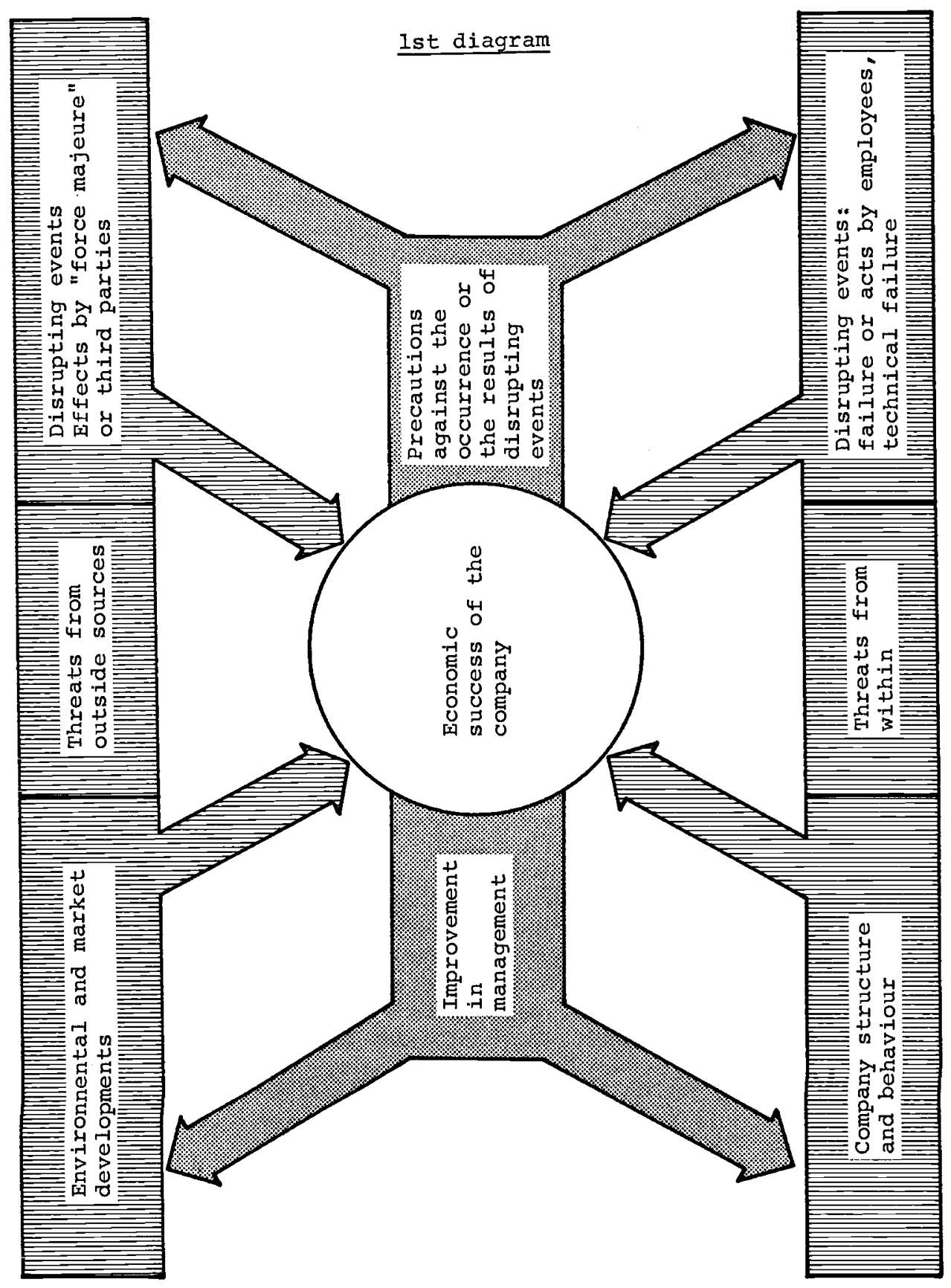




\section{Services to increase security}

\subsection{Services which contribute towards an improvement in management}

In the future there can hardly be any integrated security concepts which cater comprehensively for both the improvement of management and at the same time provide precautions against disrupting events. Fast changes in structure, energy and raw material problems, currency crises, problems regarding trade relations with developing countries, socialistic tendencies, economic fluctuations and numerous other occurrences make it obvious that management has to face considerable risks. The measures for improving management are so differentiated in their premises that we must limit ourselves here to a few individual instances of services. Their spectrum ranges from assistance in selecting management staff, via instruction in management and decisionmaking methods and basic know-how, to the preparation of current information and actual management consultancy. The individual services are not new; in future, however, they are to be directed more firmly towards increased risk management. Integrated solutions are being sought nowadays practically only in the field of disrupting events, and in this framework we want to examine the utilization of possible services.

2.2. Services in the framework of precautionary measures against the occurrence or consequences of disrupting events

\subsection{Integrated security plans}

The trend in the direction of security plans is clear. The more complex organization structures and technical equipment become, the more serious can the consequences be of disrupting events. When added to the increasing criminality, this means that effective and comprehensive precautions will have to be taken with intensified effort. Only the best coordination of all measures will lead to the greatest possible security and is most likely to guarantee the best possible cost/use ratio. It is therefore not surprising that the idea of integrated security plans are starting to become more firmly established. So far random measures were taken, frequently on the basis of losses "at the neighbour's". Where services were effectively put to use, these more often corresponded with the offer at hand than with real needs. In practice integrated plans are still being realized relatively seldom. This is above all due to the fact that business is in only very few cases in a position to develop an integrated plan itself, while the services offered are impeded by the limits set by traditional division of labour between individual bodies. At present, however, there seems to be a trend towards more cooperation between those offering the individual services. Numerous points have to be considered in order to answer the question how far a business can develop and implement a security plan without external help. Some decisive factors are: the know-how present in the business itself, the possibility of utilizing internal specialists, the degree of experience within the company compared with that offered by third parties. In this connection I can mention such items as business and specialised experience " knowledge of the business and the branch, business blindness, experience with similar companies, knowledge of the latest ideas".

However, the question " services or none" is hardly one of "either - or" in practice. In the first place the development or the realization of a security concept can 


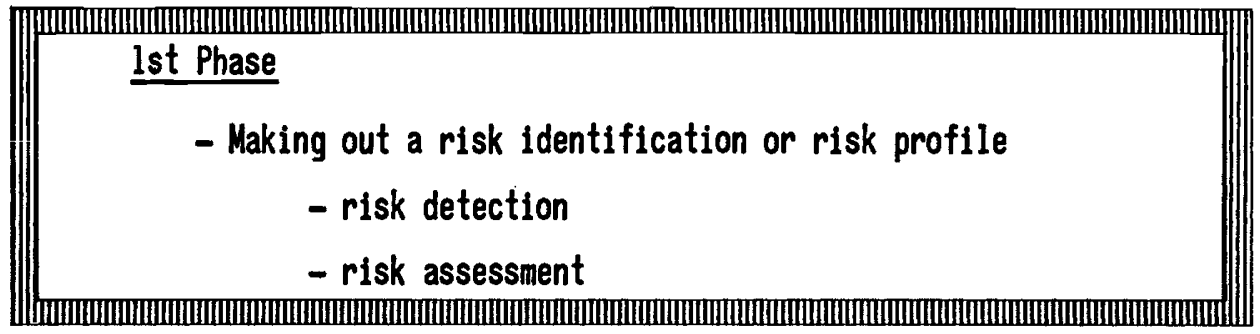

\section{2nd Phase}

- Working out a security plan

- risks against which no precautions can be taken, or which do not justify any precautions for reasons of cost/ use considerations

- risks against wich precautions must be taken (laws), or against which precautions should be taken for reasons of cost/use considerations, namely:

- technical installations

- non-technical precautions by the company itself

- use of outside services

\section{3rd Phase \\ - Planning the realization of the concept}

\section{4th Phase}

- Realization of the security concept

- realization of the company's own precautions

- equipping the technical installations

- obtaining the services provided

hardly be delegated to an outside professional service, since the increase of security represents an essential component of management, and this requires full commitment. In addition the heads of the relevant departments of the company affected will have 
to be consulted, not least in order to guarantee their complete identification with the measures taken. Secondly, the setting up and realization of a security plan comprises certain phases, for which a varying degree of cooperation on the part of outsiders is necessary (2nd diagram).

3rd diagram

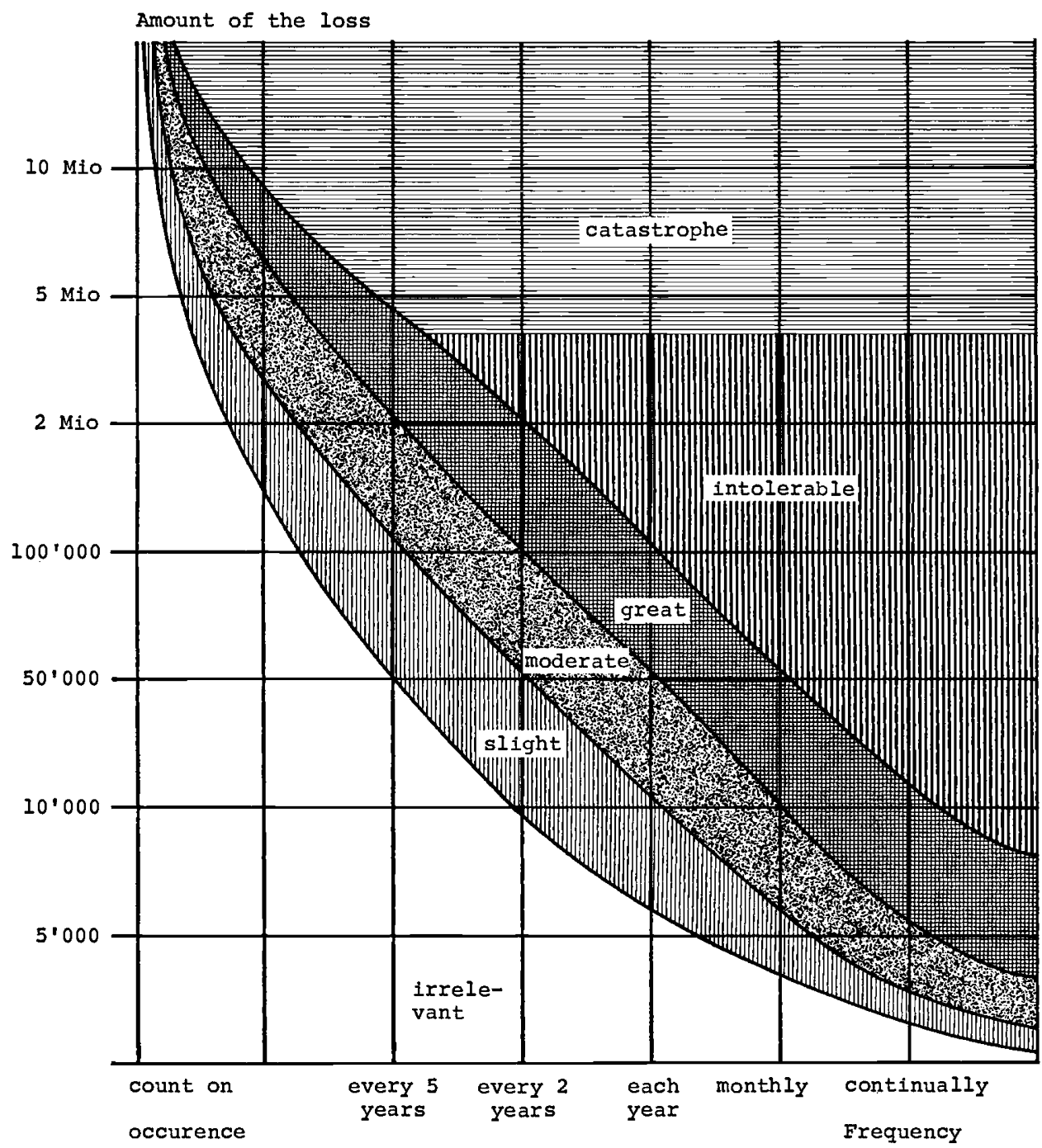

(50 years)

With the kind permission of the INSOR AG. Swiss Company for Integral Security Systems and organisation, Zurich 
I. The first phase consists of drawing up a risk identification description, or a risk profile. This is a matter of compiling and assessing the risks threatening a certain company. As the next graph (3rd diagram) tries to show diagrammatically, the frequency of disrupting events plays a role in the risk assessment, as well as the extent of the losses to be expected: thus risk is seen as a function of frequency and extent of damage. One might classify the risks correspondingly as irrelevant, slight, moderate, great, intolerable and catastrophe risks. In this connection the effects of a cumulation of disrupting events is to be taken into account. Also the effect in non-material area are quite conceivable.

It can be assumed that every company has done basic thinking on its risk situation. As a survey* of 1,143 companies from all branches of the economy in the U.S.A. has demonstrated, practically all the companies questioned have so far neglected to make an analysis of the total risk situation in their business, and most of them have no idea what it should include. In Europe the situation is hardly very different. This state of affairs may be a hint that only few companies are at present in a position to make an all-round analysis on their own. Often risk identification is attempted which is not sufficiently comprehensive, or which initially takes account of certain type of measures to be taken on the strength of preconceived ideas. It is particularly in this first phase therefore that outside professional services are justified.

II. The second phase consists of working out a security concept where professional outside assistance and pure consulting as well as an extensive compilation of the concept should be considered. A security concept is not only the result of risk identification (diagram 4) but also of other influencing factors. Mention should also be made here of legal provisions, which for instance make fire prevention and filtering of waste gases compulsory. Furhermore the subjective need for protection plays an important part. The less readiness or possibility to bear the risks oneself there is, the greater is the subjective need for protection. It is the available measures which create the final factor of influence. Here the question arises if possible measures exist at all, and if so what they cost and what contribution they are able to make towards increased security.

The security plan (diagram 2) worked out in consideration of these influencing factors, excludes those risks against which no precautions can be taken, or those which do not justify any precautions for reasons of cost/use considerations. At the same time it defines how far the individual measures go and what type they should be. Those in question are:

- technical installations - such as fire warning systems and extinguishers, admission checks and building-site precautions,

- non-technical precautions by the company itself, such as the setting up of an emergency organization or the training of personnel for emergencies, as well as

- using outside services, such as security personnel or insurances.

* Business Insurance, N. 21, October 18, 1976, p. 4. 
Factors influencing the security concept
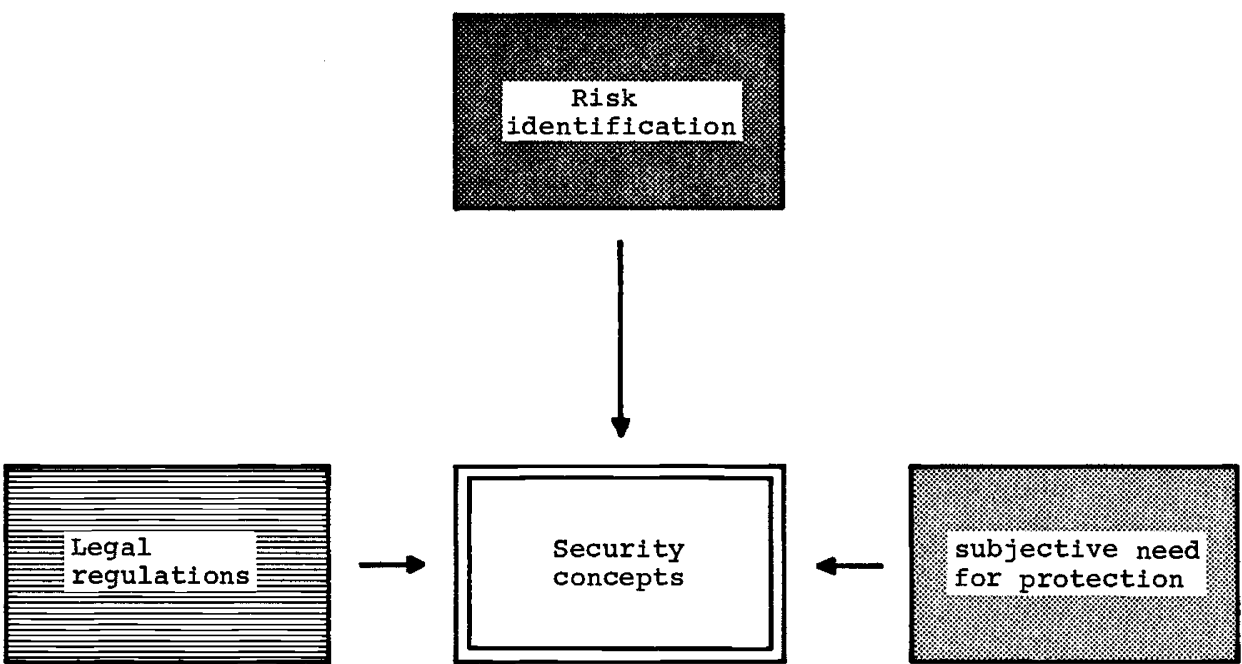

The security plan must also be made subject to a cost/use analysis from an overall point of view. If deletions have to be made to the all-round plan, alternative solutions must be found, at least in certain areas.

III. In the third phase the realization of the concept has to be planned, i.e. to define when and what measures are to be taken. It is essential that in this phase priorities should be set with a view to time and relevance.

Planning and realizing the concept may also be delegated to an outside service organization. The all-round operations of a service organization from the first to the third phase is called "general planning". 
IV. The outside service organization's efforts, however, go increasingly beyond general planning, because as a "general contractor" they also turn to the implementation of security concepts - and thereby the fourth phase. The company itself must take its own precautions, the general contractor can - if need be - exercise an advisory function.

\section{$\underline{5 \text { th diagram }}$}

\section{Threat to the company}

\section{Point of application for precautions}
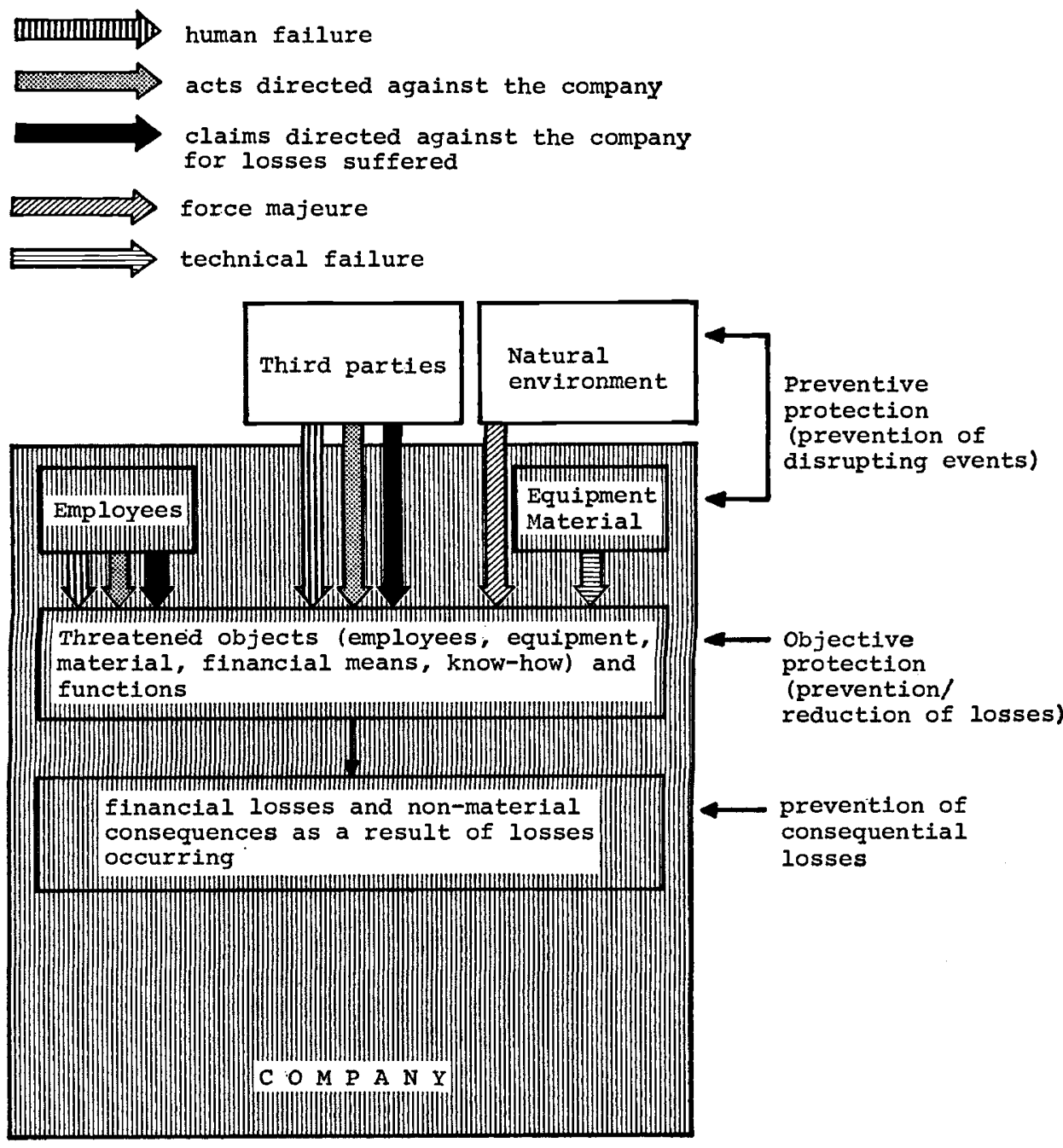
The latter may be entrusted with the technical installations, and the outside service organization with the management of the project.

So far we have tried to explain how outside services may be utilized for the working out and realization of an all-round concept. Within the scope of its realization the individual service organizations will themselves become a component of the security plan. Let us look more closely at these services, specifically designed to counter individual threats.

\subsection{Services designed to counter individual threats}

Let us take another look at the diagram shown at the beginning. According to this the threats may come from the business itself or also from outside. In the first case (diagram 5) they stem from the employees, the equipment or from the material used, in the second case from third parties or from the natural environment. As a result, one point of application for precautions is where the threat originates, in which case an attempt should be made to forestall the occurrence of disrupting events by means of preventive measures. The threatened objects are a second point of application : these are, for instance, employees (if I may be allowed in this connection to call people " objects"), equipment, material, financial means, know-how — or the threatened functions within the enterprise. This is a question of defining object protection measures. These are to prevent or lessen losses caused by the occurrence of disrupting events.

Finally any loss occurring leads to financial losses, which according to their extent, can ever threaten the very existence of the enterprise. There are also frequently nonmaterial consequences, such as loss of prestige, effects on the market position, etc. A third point of application for precaution lies in the protection against the consequences resulting from losses.

We would like to group together the services which follow according to these three points of application. On the one hand, one can look at the possible role of outside services within the scope of any imaginable precautions, on the other hand one can insist on the current relevance of certain outside services, and other precalitions in the light of important development trends.

\subsection{Services providing preventive protection}

First we will turn to services providing preventive protection.

\section{a) Employees}

Now we want to deal with risks arising in connection with employees. Personnel whose failings can have very serious consequences, as well as personnel whose work and knowledge can offer exceptional opportunities for criminal actions, must be selected with particular care. This requirement seems obvious, it is however questionable if it is always adequately followed.

The increasing complexity of business operations favours errors, and these - on account of the application of larger and more complex technical equipment and the use of more and more dangerous materials - have increasingly graver potential consequences. As far as the readiness to act criminally against one's own company is concerned, this appears to be growing too. The selection of reliable personnel and employees who are able to cope with the stress situations arising is therefore of 
considerable importance. The spectrum of services available for this purpose is, however, very limited. Those in question are inquiry offices, employment agencies, psychological and psychotechnical testing.

Services which are directed towards influencing members of the staff already recruited, play a rather modest role. Training and instruction of personnel is mainly a task of the company itself. It is often provided as an aid by firms supplying certain equipment. Outside services are seldom used for the purpose of supervising or controlling employees; here technical installations or company internal methods are a more frequent possibility - such as the duty of a leading employee to fulfil a controlling function.

Claims for compensation of employees brought against the company arise as a result of damage to health caused by harmful substances or as a result of inadequate safety precautions. Here, in addition to technical equipment, services may be considered to take necessary measures, and to give advice on accident prevention.

\section{b) Equipment, material}

The dangers which arise from the use of technical equipment or material employed, are becoming topical especially in connection with human error. In principle the same applies as was said before with regard to larger and more complex technical equipment and more dangerous materials. In the case of rare occurrences of independent technical failures too, the same tendencies are responsible for the loss potential becoming even greater in future. Avoiding technical failures at their source is, of course, a matter of the appropriate materials, technical construction and production processes used.

At the same time, however, services such as testing, supervision and maintenance play an important part; they are often provided as an additional service by the suppliers. Besides there are also firms who are specialized in services, as servicing companies for example. Then material testing must not be forgotten, which is also carried out externally, that is as a service.

\section{c) Third parties}

There can hardly be any possibilities for effective measures against threats from third parties, especially where human error or actions against the company are concerned. As the dangers originating in criminal action, such as robbery, capturing hostages, blackmail, sabotage, espionage, etc. are continually becoming greater, however, special attention should be given to the protection of objects.

As regards dangers in the form of claims by injured third parties, a wide range of precautions to prevent harmful influences is possible ; mention is made, for example, of injurious substances being emitted, or noise nuisance. State injuctions and sanctions are also of increasing importance as the result of more severe environmental legislation. In both cases these are technical precautions, however, which we do not wish to deal with in detail here.

\section{d) Natural environment}

In passing it should be mentioned that precautions against force majeure have always existed in the protection of the objects themselves : here there is no possibility of countering the origin of the threat. 


\subsection{Services providing protection for the objects themselves}

We shall now turn to services providing protection for the objects themselves. The protection of objects consists on the one hand of measures which make it possible to identify risk situations in good time. On the other hand the countermeasures realized or those to be taken after the situation has arisen also fall under the definition of protection of objects. In this talk we can leave out all building construction precautions against fire, explosion, water, earthquake, burglary, sabotage, etc. as well as all the purely technical precautions such as fire alarms, checks on admission, fire extinguish ing installations, safes, alarm systems, protective clothing, etc. because we are talking especially of services. Precautions in the area of "Employee training and instruction", 'Organization' and 'Handling claims for compensation' are services taking a primary place in the protection of endangered objects.

\section{a) Services in the area of 'employee training and instruction'}

The training and instruction of employees with regard to their behaviour in danger situations can be extensively handled by outside institutions. The following are some important danger situations which - according to the type of business - require more or less thorough instruction for behaviour: outbreak of fire, irruption of water, explosions, injurious substances, certain crimes from outside or within, as for instance robbery or capturing hostages. But not only such seemingly imminent or catastrophic situations arising or crimes are to be regarded as danger situations, but for example also the possibility of secret information also belongs to the essential security precautions and thus to the possible services.

\section{b) Services in the field of "organization"}

Frequently instruction on behaviour in dangerous situations or in the face of crime is part of a comprehensive emergency situation, which determines the role of each participant, and ensures the provision of the technical equipment required. Setting up such an emergency organization can be carried out by outside assistance. But other services are possible in the field of organization which help to protect endangered objects. Thus detailed organizational plans taking account of the main dangers, can be worked out for firms which are particularly endangered through robbery, sabotage, espionage, etc.

Working out plans with regard to multiple perception and locations for technical functions within the company can also be counted among the services in the field of organization. The security of external auxiliary possibilities, such as the possibility of utilizing an external computer or the permanent external storage of endangered objects (example : fungible securities or important data) also belongs to these services.

Naturally other services may be utilized within the scope of organizational plans for the protection of endangered objects, which I do not wish to deal with in detail. Mention should however be made of the guarding of all possible objects by external institutions as well as guarded transport.

\section{c) Services in the area of 'procedure in the face of claims for compensation'}

It should be observed, in connection with the procedure in the face of claims for compensation, that not only environmental hazards are constantly growing as a result 
of our technical developments; also the legal possibilities for injured claimants to establish their claims have continued to expand (stricter legislation and judicial practice). The right procedure, in particular for warding off unwarranted claims, is gaining in importance. The essential services to be put into effect here are legal counsel, conducting of lawsuits by lawyers, and the payments made by liabilities insurers.

\subsection{Services which afford protection against the consequences of losses}

Finally we would like to turn to those services which afford protection against the consequences of losses. In its wide sense this category could also include services which provide more financial scope. Such services are in general not utilized in the sense of making provision against possible disruptions, but in order to guarantee business commitments. The classical safeguards against the financial consequences of losses arising does not consist of an extension of financial scope, but in diverting the financial risk. Diverting the risks to business partners contractually and the legal counselling involved here, are only by the way. It is, naturally, much more important - at least with a view to services - to divert the risks to insurance companies. I should only like to make a few final remarks in this connection, because this is hardly the right occasion to go into particular types of insurance in detail :

- In certain cases insurance may be the only effective precaution. In other cases it plays a subsidiary role when other preventive or protective measures have failed. Thus precautions which reduce the probability that insurance will be claimed are rewarded by a reduction in premiums, discounts, etc.

- Insurance is not able to cover all the possible financial consequences in each case. Apart from the fact that the coverage of certain risks are not justified for reasons of cost, there are also cases where no coverage is offered. So insurance payments cannot exceed a certain maximum in most liability insurances.

- Nowadays the insurer's services consist not only of accepting financial risks, but also all-round counselling, which reveals what can and should be insured. Insurance is being incorporated more and more into integrated security concepts. In this connection insurance companies are in part beginning to offer comprehensive security plans themselves, or partly they are joining various types of other companies for the purpose of working out integrated security plans.

And now finally a few remarks on the non-material consequences of losses arising. In many cases it is hardly possible to take precautions here. The loss of a certain position on the market after a long break in production can often hardly be avoided. Another different case is one where a loss of image may result from a third party claim for losses incurred. Here public relations can at least mitigate the extent of the loss, such public relations campaigns can, of course, also be organized by outside assistance.

\section{Summary}

Let me now summarize the most important points briefly.

1. The threat to the economic success of the company is clearly becoming greater, both from the point of view of the market as well as through disrupting events. There 
6th diagram

increasing threat to the succes of the company

greater need for security precautions

increased security = improvement in the chances of the company's success

$\longrightarrow$ essential management task, which consists not only in the provision against disrupting events, but also in improved management itself (marketing, management structure, behaviour)

security as a matter of concern for top management

$\longrightarrow$ full commitment of management executives

$\longrightarrow$ comprehensive examination to ensure the best possible cost/use ratio

dual role of the services

$\longrightarrow$ working out and realization of integrated security concepts

$\longrightarrow$ components of security concepts

continuous change in conditions affecting the existence of the company

$\longrightarrow$ mastery of the security problem as a permanent task for the management

is a certain correlation insofar as a company, whose profits become worse on account of factors in the market, is far less in a position to absorb the disrupting events. The need for safety precautions will grow corresponding to the developments.

2. Since increase in security at the same time means an improvement in chances of economic success, it is clear that security represents an important element in management. Threats or security are matters for overall consideration. Top management will 
be concerned with security. A gain in the degree of security is not effected only by means or provision against the occurrence or the consequences of disrupting events, but also by means of an improvement in management.

3. The role of services is a dual one: firstly outside assistance may be called in for working out and realizing integrated security concepts. Secondly services can be a component of integrated security plans, besides other safety precautions. Most of these last-mentioned services have been applied for a long time. Therefore such outside consultants also have many years of experience with respect to certain services. On the other hand, services as an integrated security concept are comparatively new, since an individual company does not have the necessary know-how and the resources required, and because the association of several companies will first have to overcome existing structures. Nevertheless the first such associations have been formed, especially in the USA. In Switzerland one company has emerged from such an association, engaged with the setting up and realization of security concepts extending beyond all four phases. It will now be necessary to obtain comprehensive experience, not only with respect to compilation and realization but also with respect to periodic revision. Because those very changes in the internal and external conditions of a company's existence, which have made the creation of integrated plans so urgent, will also lead to a shifting in the significance of the various types of threats. So the problem is never definitely solved. Its management is more likely to be a permanent task. 